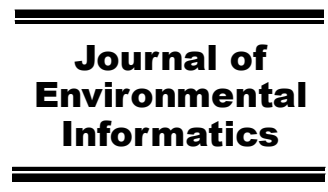

www.iseis.org/jei

\title{
Meteorological Analysis Systems in North-East Spain: Validation of SAFRAN and SPAN
}

\author{
P. Quintana-Seguí ${ }^{1, *}$, C. Peral ${ }^{2}$, M. Turco ${ }^{3}$, M. C. Llasat ${ }^{4}$, and E. Martin ${ }^{5,6}$ \\ ${ }^{I}$ Observatori de l'Ebre (OE), Universitat Ramon Lull-CSIC, Roquetes 43520, Spain \\ ${ }^{2}$ Agencia Estatal de Meteorología, Madrid 28040, Spain \\ ${ }^{3}$ Barcelona Supercomputing Center-Centro Nacional de Supercomputación (BSC-CNS), Barcelona 08034, Spain \\ ${ }^{4}$ Departament d'Astronomia i Meteorologia, Universitat de Barcelona, Barcelona 08028, Spain \\ ${ }^{5}$ CNRM, UMR 3589, Météo-France/CNRS, Toulouse 31057, France \\ ${ }^{6} I R S T E A$, UR RECOVER, Aix-en-Provence 13182, France
}

Received May 30, 2014; revised April 28, 2015; accepted June 28, 2015; published online June 14, 2016

\begin{abstract}
We present an application and validation of the SAFRAN meteorological analysis system for north-east Spain. SAFRAN is also compared to the SPAN analysis system and the meteorological model HIRLAM-HNR, both operational at AEMET. This application of SAFRAN is intended for hydrological studies. This is the first study that shows an application of SAFRAN outside of France and that compares it with SPAN. This is also the first article validating SPAN's rainfall values. Using one year of observational data, the results show that both SAFRAN and SPAN have a similar performance, which is also similar to SAFRAN's performance in France. Thus, SAFRAN and SPAN are both good tools to force land surface models at high resolution in the area of SAFRAN works under the assumption of the existence of climatically homogeneous zones. Two different sets of zones were tested, one based on the AEMET meteorological warning zones and another one based on hydrological catchments. Better results were obtained when using meteorological warning zones. However, the difference is small. In north-east Spain, SAFRAN has the same limitations that were previously shown in France: the spatial structure of the fields is not realistic enough and wind speed is underestimated. As expected, both SAFRAN and SPAN work better in flat areas than over areas of steep relief. This can be a problem in hydrological studies, especially for the Ebro river basin, where most of the runoff is generated in the Pyrenees.
\end{abstract}

Keywords: meteorological analysis, high resolution grid, optimal interpolation, SAFRAN, SPAN, HIRLAM

\section{Introduction}

Water is an essential resource which is necessary to sustain our society. However, it also represents a significant risk, as we are exposed to its extreme conditions - droughts and floods. The impact of these extremes is increasing due to our increased vulnerability (Ruin et al., 2008; Llasat et al., 2010a). This is especially true for the Mediterranean coast of Spain (Llasat et al., 2005, 2009, 2010b, 2008; Majone et al., 2012) as this situation is taking place in a context of climate change, which will have intense effects on the Mediterranean area (Diffenbaugh and Giorgi, 2012). As a consequence, water resources may decrease in quantity and become more variable in a context of greater demand (Iglesias et al., 2007, 2009) due to changes in the mean and the extremes of precipitation and river flow values (Sumner et al., 2003; Rodríguez, 2005; Bürger et al., 2007; Llebot, 2010; Quintana Seguí et al., 2010;

* Corresponding author. Tel: +34 977500511; Fax: +34 977504660. E-mail address: pquintana@obsebre.es (P. Quintana-Seguí).

ISSN: $1726-2135$ print/1684-8799 online

(C) 2016 ISEIS All rights reserved. doi: 10.3808/jei.201600335
Quintana-Seguí et al., 2011; Estrela et al., 2012). In fact, these changes are already being observed (López-Moreno et al., 2010; Turco and Llasat, 2011; Lorenzo-Lacruz et al., 2012; Turco et al., 2014). As a consequence, a very good knowledge of the hydrometeorological processes that take place on the continental surface is key for our society.

The international scientific community is organizing itself in order to tackle these issues more effectively. In the Mediterranean context, the international program HyMeX (Drobinski et al., 2013) is working on improving our comprehension of the Mediterranean water cycle using a multidisciplinary and multiscale approach. The objectives of HyMeX are close to those of the FP7 project eartH2Observe (http:// www.earthobserve.eu), which studies the global hydrological cycle. The eartH2Observe project has several case studies. One of them is set in Spain and will study drought processes by means of land surface model simulations.

However, in order to carry out these simulations, a high quality atmospheric forcing is needed. Without good atmospheric data, the conclusions of studies made using land surface models would not be suitable, even if the land surface models correctly reproduce the relevant processes. As a con- 
sequence, it is essential to have a high quality, high resolution gridded dataset of screen level atmospheric variables. In fact, such a dataset is very valuable for many different applications, including the study of meteorological events (Llasat et al., 2014), the verification of meteorological models and reanalyses (Szczypta et al., 2011) or the statistical downscaling of climate models (Boé et al., 2009; Quintana Seguí et al., 2010; Quintana-Seguí et al., 2011; Turco et al., 2011; Vrac et al., 2012). In the field of land surface modeling, such data is important in applications related to remote sensing data validation and assimilation (Albergel et al., 2008; Paris Anguela et al., 2008; Draper et al., 2009, 2011; Rüdiger et al., 2009), vegetation and agricultural modeling (Brut et al., 2009; Calvet et al., 2012; Claverie et al., 2012), road condition modeling (Bouilloud et al., 2009) and hydrology (Habets et al., 2008, 2009; Thirel et al., 2008; Gascoin et al., 2009; Korkmaz et al., 2009; Céron et al., 2010; Javelle et al., 2010; Velázquez et al., 2010; Brochero et al., 2011; Lafaysse et al., 2011; Sauquet and Catalogne, 2011), among others. Finally, such databases are also interesting for biological environmental modeling (Bru et al., 2011; Dequiedt et al., 2011; Ranjard et al., 2013).

The majority of the papers mentioned in the previous paragraph use atmospheric gridded data created with the SAFRAN analysis system (Durand et al., 1993, 1999; QuintanaSeguí et al., 2008; Vidal et al., 2010), which was developed by Météo-France and, until now, has only been available in France. One of the strengths of SAFRAN is that it is able to analyze all the variables that are needed to force complex land surface models (temperature, precipitation, wind speed, relative humidity and cloudiness). Unfortunately, it is rare to find such complete databases.

Reanalyses such as ERA-40 (Uppala et al., 2005) or its newer successor, ERA-Interim (Dee et al., 2011), would be very practical for such studies (as they are global products) if they had sufficient resolution. Unfortunately, ERA-Interim has a spatial resolution of about $80 \mathrm{~km}$, and ERA-40's resolution is even lower. Such resolutions are one order of magnitude too coarse for the aforementioned applications, which are the applications we are targeting in our work. However, even in the case that ERA products had a higher resolution, it is not clear whether they would be better or worse than SAFRAN (at least regarding some variables) and, thus, there is room for other approaches.

The E-OBS dataset (Haylock et al., 2008) is another product that could be used to force land surface models. It covers Europe, thus allowing for regional applications that cover several countries. However, its resolution of $25 \mathrm{~km}$ is still too coarse, even though it is better than that of ERA-Interim. Furthermore, it uses too few stations in Spain (see Figure 1 of Haylock et al. 2008) and it is too limited in its number of variables, only providing data for temperature, precipitation (Haylock et al., 2008) and sea level pressure (van den Besselaar et al., 2011). In Spain there is a similar dataset for temperature and precipitation, called Spain02 (Herrera et al., 2012), which offers very good quality data. It uses data from thousands of stations, but is also insufficient in the number of variables and resolution $(20 \mathrm{~km})$.
Mesoscale analysis systems which are more similar to SAFRAN include: CANARI (Taillefer, 2002), part of the HARMONIE non-hydrostatic convection-permitting weather prediction system ${ }^{1}$; SPAN (Rodríguez et al., 2003; Cansado et al., 2004), developed and used by the Spanish State Meteorological Agency (AEMET); MESAN (Häggmark et al., 2000), developed by the Swedish Meteorological and Hydrological Institute (SMHI); or MESCAN (Soci and Bazile, 2013), recently developed within the EURO4M project. These different analysis systems are similar and based on optimal interpolation. What is more important is that they all produce the needed variables at high resolution. Thus, any of them would be useful for our objectives. MESCAN, which improves the state of the art by building upon MESAN and SAFRAN and covers the whole of Europe, seems to be the best candidate for our needs. However, it has not yet been fully validated and, to date, only 4 years of data are available.

As a consequence we decided to use the well-tested SAFRAN and SPAN. One of the benefits of implementing these analysis systems is that we have control over the observed data used, ensuring that the whole AEMET dataset, and not only a subset, is included.

In this study we present the application of the SAFRAN meteorological analysis system to north-east Spain. Llasat et al. (2014) used our implementation of SAFRAN to study an interesting snow event that took place in Catalonia (located in north-east Spain), but SAFRAN has not yet been validated in this area of study. In this study SAFRAN is compared with SPAN and with the HIRLAM-HNR meteorological model (Navascués et al., 2013), operational at AEMET. Both SAFRAN and SPAN are compared and validated with observed data. This is the first study that validates SAFRAN outside of France and it is the first time that SAFRAN has been compared with SPAN. This is also the first study that validates SPAN's rainfall results. Furthermore, the study allows us to compare the performance of SAFRAN in France with SAFRAN in Spain.

This article is structured as follows. The area of study is described in Section 2. The analysis systems and other data used in the study are presented in Section 3. In Section 4, the methods used for our comparison and validation are shown. The results are presented and discussed in Section 5. Finally, we offer our conclusions in Section 6.

\section{Study Area}

The area selected for our study (black box in the maps of Figure 1) covers north-eastern Spain, including the Ebro basin which is the main hydrological unit of the area. This is a particularly interesting area because of its high spatial heterogeneity. The basin is bounded to the north by the Pyrenees and the Cantabrian Range and to the south by the Iberian System. To the east, the Catalan Coastal Range separates the basin

\footnotetext{
${ }^{1}$ http://www.hirlam.org/index.php/hirlam-programme-53/general-modeldescription/mesoscale-harmonie
} 
(a) Meteorological Warning Zones

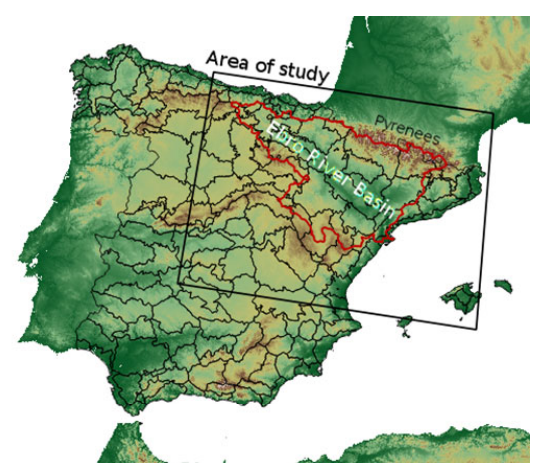

(b) River Basins

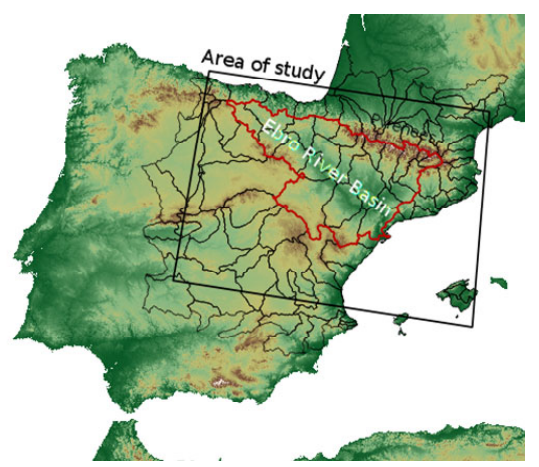

(c) Relief (m) on the $5 \mathrm{~km}$ grid

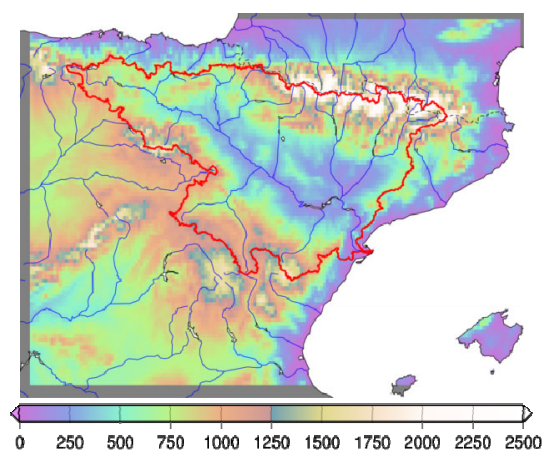

Figure 1. Area of study (black box on the maps). Panes (a) and (b) show the climatically homogeneous zones used in the SAFRAN analysis (black lines): the first set is based on meteorological warning zones and the other one is based on river basins. Pane (c) shows the relief on the $5 \mathrm{~km}$ grid. The main rivers are also shown (in blue). The Ebro river basin is shown in red in the three panes.

from the Mediterranean coast. This topographic configuration, together with both Atlantic and Mediterranean influences, is the cause of the strong spatial variability of precipitation seen here. For example, annual rainfall can vary between approximately $2500 \mathrm{~mm}$ in some areas of the Pyrenees to $300 \mathrm{~mm}$ in the center of the Ebro valley (AEMET, 2011). In addition, the temporal variability is also high, on both the inter-annual and seasonal scales. This variability is related to the Mediterranean oscillation (MO), which is linked (with seasonal dependence) to the Northern Hemisphere teleconnection modes of the Arctic oscillation (AO) and North Atlantic oscillation (NAO) (Dünkeloh and Jacobeit, 2003). All this makes our area of study particularly challenging and interesting for the validation of meteorological analysis systems.

\section{Models and Data}

In the next section we present the analysis systems, the databases generated with them, the meteorological model that was used as a first guess and baseline for the comparison and, finally, the observed data used for both carrying out the analysis and validating it.

The time period of this study is a complete hydrological year, which starts on the 1st of September 2009 and ends on the 31 st of August 2010.

\subsection{SAFRAN}

The main objective of SAFRAN is to produce an estimation of the meteorological screen-level variables necessary to force a soil-vegetation-atmosphere transfer model (SVAT). To this end, SAFRAN uses all available observations and a first guess, which are the spatial fields of a numerical prediction model at different levels.

SAFRAN was initially created with the objective of forcing the snow model CROCUS (Brun et al., 1989) in the French Alps in order to improve avalanche prediction. Nowadays there are two operational versions of SAFRAN, both in France: SAFRAN/A (Durand et al., 2009) is used for avalanche prediction and SAFRAN/F (Quintana-Seguí et al., 2008;
Vidal et al., 2010) is the version used for the simulation of the water balance of France. The main differences between both systems are that SAFRAN/A is able to take into account the different aspects of a massif and, also, that it is able to take into account hourly data thanks to a recent variational algorithm.

For most parameters, SAFRAN uses an optimal interpolation method (Gandin, 1966). Downward solar and atmospheric radiation are an exception as, due to the lack of observations, these are calculated by means of a radiative transfer model (Ritter and Geleyn, 1992). One of its main characteristics is the use of "climatically homogeneous" zones as its main working area. These zones have irregular shapes and they cover an area which is, generally, smaller than $1000 \mathrm{~km}^{2}$. They should have a weak horizontal gradient, specially for precipitation. That is, the variables should be quite homogeneous within each zone. The zones have several vertical levels - one every $300 \mathrm{~m}$. SAFRAN estimates one value of each variable for each vertical level of the zone. Then, these values are spatially interpolated to a regular grid, according to their altitude. Thus, within the same zone, the values of the variables are only different if the corresponding grid points have different altitudes. However, the zones are not completely isolated. If necessary, observations from outside the zone may be used if fewer than two observations are present in the analyzed zone. If the climatically homogeneous zones are cleverly delimited, SAFRAN might perform well in mountain areas.

The analysis within each zone has two steps. First, the vertical profiles of each variable are analyzed. Afterwards, the surface values are calculated. The method is inspired by Gandin (1966) and uses algorithms that take into account the geographical distribution of the meteorological stations and the correlations between them. The detailed method is explained by Durand et al. (1993). Hereafter its main characteristics will be presented. In order to estimate $Y_{k}^{a}$ (where $a$ stands for analysis) which is localized at point $k$, with observations $X_{i}^{o}$ (situated at $i$ ), we look for the weights $P_{i}$ that:

$Y_{k}^{a}=Y_{k}^{g}+\sum_{i=1}^{N} P_{i}\left(X_{i}^{o}-X_{i}^{g}\right)$ 
The number of observations is $N$ and the quantities $Y_{k}^{g}$ and $X_{i}^{g}$ correspond to the first guess $(g)$, which, in our case, will be the output of a meteorological model. The model statistical structures correspond to the errors $(\varepsilon)$. Therefore, the weights are calculated solving the following linear system of covariance:

$$
\sum_{i=1}^{N} P_{i} \operatorname{Cov}\left(\left(\varepsilon X_{i}^{o}-\varepsilon X_{i}^{g}\right)\left(\varepsilon X_{j}^{o}-\varepsilon X_{j}^{g}\right)\right)=\operatorname{Cov}\left(\varepsilon X_{k}^{g} \varepsilon X_{j}^{g}\right)
$$

The horizontal correlations are modeled using a limited series of Gaussian functions coupled to another model of vertical correlations. Equations (1) and (2) are for scalars.

The values at the surface are calculated using a simpler method. First, the values of the first guess are modified taking into account the previously calculated vertical profile. Then, the weights are calculated taking into account only the distance between points $i$ and $k$. The method is iterative and the result of each iteration is used as the guess for the next one. In the last iteration, the observations only influence the closest point.

This procedure is applied to temperature, humidity, wind and cloudiness. For precipitation, the same method is used, but with some changes, including the fact that we work with daily data. Furthermore, in this case there is no vertical correlation and we impose that the result respects a certain vertical structure (Durand, 1995).

An important fact to take into account is that SAFRAN's algorithm sets a maximum number of stations for each variable and zone (Quintana-Seguí, 2011): 12 stations of temperature, 8 of humidity, 12 of wind, 8 of cloudiness and 16 of precipitation

SAFRAN/E is the Spanish application of SAFRAN. It is based on SAFRAN/F, with an almost identical analysis code. Some changes were introduced in order to use AEMET's operational meteorological model as the first guess.

With the objective of testing the sensitivity of SAFRAN to the map of climatically homogeneous zones, two different zone sets were used - one based on AEMET's meteorological warning zones and another one based on river basins (Figure 1). This comparison is important because, to the best of our knowledge, when SAFRAN was extended to the whole of France, only one set of zones was tested. Therefore it is not yet known how sensitive SAFRAN is to a specific zone set.

Furthermore, the error introduced by the spatial interpolation to a regular grid of 0.05 degrees of resolution was also studied. This test is important because SAFRAN will always be used on regular grids. Thus, to compare SAFRAN with the observations, it was vertically interpolated to the exact altitude of the meteorological station. Then, it was also interpolated to the altitude of the corresponding grid point, which will be different. This was done by taking advantage of the fact that SAFRAN has vertical levels (one every $300 \mathrm{~m}$ ). Therefore, there will be a difference in altitude between both cases, which will introduce an error. In fact, the first case is the equivalent of working with a regular grid of infinite resolution.
The second case, the realistic one, corresponds to our grid of 0.05 degrees of resolution. These two tests have been performed in France by Quintana-Seguí et al. (2008), focusing on validation at the altitude of the stations, and by Vidal et al. (2010), focusing on validation at the altitude of the grid cells. Figure 1.c shows the relief corresponding to the 0.05 degree resolution grid used in this study.

Table 1. Abbreviations Used to Refer to the Different Configurations of Safran Used in this Study

\begin{tabular}{lll}
\hline Zones & Vertical Interpolation & Abbreviation \\
\hline $\begin{array}{l}\text { Meteorological } \\
\text { Warning Zones (M) }\end{array}$ & $\begin{array}{l}\text { Altitude of the } \\
\text { observation }\end{array}$ & $\mathrm{SF}_{\mathrm{m}}^{\mathrm{o}}$ \\
$\begin{array}{l}\text { Meteorological } \\
\text { Warning Zones (M) }\end{array}$ & $\begin{array}{l}\text { Altitude of the } \\
\text { grid cell }\end{array}$ & $\mathrm{SF}_{\mathrm{m}}^{\mathrm{g}}$ \\
$\begin{array}{l}\text { Zones based on } \\
\text { river basins (B) }\end{array}$ & $\begin{array}{l}\text { Altitude of the } \\
\text { observation }\end{array}$ & $\mathrm{SF}_{\mathrm{b}}^{\mathrm{o}}$ \\
$\begin{array}{l}\text { Zones based on } \\
\text { river basins (B) }\end{array}$ & $\begin{array}{l}\text { Altitude of the } \\
\text { grid cell }\end{array}$ & $\mathrm{SF}_{\mathrm{b}}^{\mathrm{g}}$ \\
\hline
\end{tabular}

Table 1 shows the four configurations of SAFRAN that were used in this study. Note that SAFRAN will often be referred to as SF.

\subsection{SPAN}

SPAN (Surface Parameters Analysis) (Navascués et al., 2003; Rodríguez et al., 2003; Cansado et al., 2004) is the analysis system for surface variables of the prediction and data assimilation system HIRLAM. It was developed by AEMET and it is operational in all the countries that are members of the numerical weather prediction consortium HIRLAM. SPA$\mathrm{N}$ was developed with the main objective of completing the work on prediction modules destined to improve the simulation of the processes of exchange between the continental surface and the atmosphere using a scheme with tiles based on the ISBA surface scheme (Navascués et al., 2003; Rodríguez et al., 2003). In this way, SPAN is used by HIRLAM in its data assimilation cycle. In its operational application in Spain, it uses, as its first guess, the short range prediction of the HIRLAM HNR model (Navascués et al., 2013) and is able to analyze sea surface temperature, the fraction of sea ice, snow thickness (Cansado et al., 2004), soil temperature and wetness, and $2 \mathrm{~m}$ temperature and humidity. These last two variables allow us to analyze the soil temperature and water content, which are not observed (Navascués et al., 2003; Rodríguez et al., 2003). Later, AEMET improved SPAN in order to be able to use it independently from the prediction chain and also introduced new variables to the analysis: sea level pressure (Cansado, 2002), $10 \mathrm{~m}$ wind, bivariance in horizontal components (Cansado, 2003) and precipitation. These last three variables are not assimilated in the operational model, but they are used for diagnostics, validation of the model and other applications. SPAN is used to calculate forest fire risk, and it is also used as a support tool for prediction, as well as in order to warn about adverse road conditions. 
SPAN uses optimal interpolation for all the variables used in this study. It also includes a vertical interpolation procedure in order to reduce the values of the vertical profile of the first guess (wind, temperature, humidity and surface pressure) to the altitude of the observation point, taking stability into account (Navascués, 1997); this is specially important in areas with a complex terrain, where the actual orography is different from the model's.

The structure functions of the error autocorrelation model of the first guess introduce anisotropy due to the orography (Navascués, 1997) and present seasonal and diurnal dependencies. For each one of the variables, the error statistics of the first guess and the observations are calculated using historical series of innovations (observations minus the first guess) obtained from the operational runs of AEMET's HIRLAM. The error autocorrelation function model of the first guess depends on the analyzed variable:

- $\quad 2 \mathrm{~m}$ temperature and relative humidity: a combination of two 3rd order autoregressive functions is used in order to take into account the large and small scales of the errors of the first guess (parameterized according to the season and time) (Martín and Navascués, 2004).

- Sea level pressure: a product of 2 Gaussian functions is used in order to take into account the vertical and horizontal dependence of this variable (Cansado, 2002).

- 10 m wind: Gaussian functions are used in order to independently represent the errors of the velocity potential and the stream function of the first guess (Cansado, 2003).

- Precipitation: a product of 2 Gaussian functions is used in order to take into account the vertical and horizontal dependence.

Studies have been done using independent observed data of $2 \mathrm{~m}$ temperature on the Iberian Peninsula and it has been observed that introducing orographic anisotropy reduces analysis errors (Navascués, 1997). Introducing this factor improves the quality of the analysis in areas of complex terrain, as is the case of Spain. Some studies show that there are other sources of anisotropy. For example, the stations situated in irrigated areas present a greater correlation and are decoupled from those located in non-irrigated cropland or forests. As a consequence, land use could be included as a source of anisotropy, but this would need a high resolution physiographic database.

Another advantage of this analysis method is that it includes a sequential quality control comparing the observed data with the first guess and with its neighbors. Rejected data is not included in the analysis.

In order to avoid computational costs, the surface analysis of HIRLAM is based on spatial analysis boxes which reduce the size of the relevant spatial domain to obtain the analysis of a given grid point. Thus, the analysis is performed independently for each box, but the area from which the observations are taken to perform the analysis is much larger than the box itself, which guarantees the continuity between the analysis of each one of the boxes.
In this study, we carried out a coordinated exercise for precipitation. For this variable SPAN and SAFRAN use exactly the same data to perform the analysis. Furthermore, both analysis systems have used fields of null precipitation as their first guess. For the other variables, the outputs of the operational SPAN analysis chain of AEMET were used and the list of stations that were used for each analysis time could not be accessed. However, the number of stations used by both SPA$\mathrm{N}$ and SAFRAN must be very similar, or a little bit smaller for SPAN as it used almost real-time data. In this case, SPAN used 3-hourly data. Unfortunately, the data series is not continuous, as $19 \%$ of temperature, humidity and wind data are missing. SPAN.

In this paper the abbreviation SP will be used to refer to

\subsection{HIRLAM}

For both SPAN and SAFRAN, the outputs of the meteorological model HIRLAM-HNR (Navascués et al., 2013), which is operational at AEMET, were used as a first guess. The model has a resolution of 0.05 degrees. We must bear in mind that precipitation is an exception and, so, in this case fields of zero precipitation are used as a first guess.

The outputs of both analyses were also compared to HIRLAM-HNR, in order to study the analysis increases. More specifically, the $6 \mathrm{~h}$ lead forecasts for $0,6,12$ and 18 hours (UTC) were used. In this case, when the results of SAFRAN and SPAN were compared with HIRLAM, the original gridded data of HIRLAM were used, without the processing done by SAFRAN or SPAN before using it as their first guess. This means that the comparison is not done against the first guess, as this was used by the analysis algorithms. Therefore, these comparisons do not allow us to study the errors of the analysis algorithms - we are, instead, comparing final products. In this paper the abbreviation HIR will be used to refer to this model.

\subsection{Observations}

All the observed data used in this study come from AEMET's synoptic and temperature-rainfall station networks. The data available to us at the time of writing this paper was one hydrological year spanning from the 1st of September 2009 to the 31st of August 2010. This period is too short to validate the climatology of SAFRAN or SPAN, but it is long enough to test whether SAFRAN performs similarly in Spain to its use in France, as published in Quintana-Seguí et al. (2008), with two years of data.

Table 2 shows the number of available stations for each variable and its frequency in the area of study. The temperature-rainfall network is denser than the synoptic one, and therefore there are many more stations for precipitation and maximum and minimum temperatures. 6-hourly data was available at $0,6,12$, and 18 hours (which correspond to the analysis times of SAFRAN) for all the variables, except for precipitation and maximum and minimum temperatures which are daily values. 
Table 2. Available Stations with Data for Each One of the Variables Studied in the Period of Study

\begin{tabular}{lllll}
\hline Variable & Frequency & Total & Dep. & Indep. \\
\hline Precipitation & $24 \mathrm{~h}$. & 1732 & 1103 & 501 \\
Temperature & $6 \mathrm{~h}$. & 127 & 118 & \\
Maximum Temperature & $24 \mathrm{~h}$. & 1031 & & 804 \\
Minimum Temperature & $24 \mathrm{~h}$. & 1031 & & 804 \\
Relative Humidity & $6 \mathrm{~h}$. & 127 & 118 & \\
Wind Speed & $6 \mathrm{~h}$. & 127 & 118 & \\
Total Cloudiness & $6 \mathrm{~h}$. & 92 & 110 & \\
Visible radiation & $1 \mathrm{~h}$. & 21 & & 21 \\
Infrared radiation & $1 \mathrm{~h}$. & 15 & & 8 \\
\hline
\end{tabular}

*The column "Total" is the number of stations available in a geographical area defined by the parallels $39.0 \mathrm{~N}$ and $43.6 \mathrm{~N}$ and the meridians $5.0 \mathrm{~W}$ and 3.4E. "Dep." is the number of dependent stations that are located in a meteorological warning zone completely included in the aforementioned area of study. "Indep." is the number of independent stations that satisfy the same condition of being in a zone completely included in the area of study.

All these data have been divided into two datasets: a dependent one and an independent one. The dependent dataset includes the observations used to perform the analysis and is used to evaluate the analysis process. The independent dataset includes observations not used to carry out the analysis and it is used for validation purposes. In Section 0 we explain in detail how these two sets are formed.

We used hourly data for radiation. The data that were provided by AEMET did not include nocturnal values for Visible Radiation. In order to present our validation results in a way that is comparable to previous studies (Quintana-Seguí et al., 2008), nocturnal data of $0 \mathrm{~W} \mathrm{~m}^{-2}$ were added for the days that had diurnal data. Otherwise, if the comparison had only included diurnal data, the resulting means and errors would be higher and not comparable.

\section{Methodology}

SAFRAN performs an analysis every 6 hours for all variables except precipitation. Afterwards, the resulting analysis is time interpolated in order to obtain hourly data. SPAN performs its analysis every 3 hours. The results at the analysis times of SAFRAN $(0,6,12$ and 18 hours) were compared. In order to see the errors introduced by SAFRAN's interpolation the reader can read Quintana-Seguí et al. (2008), who validated SAFRAN in France.

In order to quantify the comparisons, the bias $(B)$ and the root mean square error (RMSE) were used, which are defined as follows:

$$
\begin{aligned}
& B=\frac{1}{N} \sum_{i=1}^{N}\left(y_{i}-x_{i}\right) \\
& R M S E=\sqrt{\sum_{i=1}^{N} \frac{\left(y_{i}-x_{i}\right)^{2}}{N}}
\end{aligned}
$$

where $y_{i}$ and $x_{i}$ represent the analyzed and observed values for each time step. When using the RMSE we must bear in mind that, as it is squared, it is more sensitive to large errors than to smaller ones. When SAFRAN or SPAN are compared with dependent data, the acronym RMSD is used, instead of RMSE, as they are not errors, but differences. In all cases, when comparing with the observations, the observations are the reference dataset.

In some cases, it is easier to interpret the results if they are normalized. The relative bias and RMSE are defined as follows:

$$
\begin{aligned}
& B_{r}=100 \frac{B}{\bar{x}} \\
& R M S E_{r}=100 \frac{R M S E}{\bar{x}}
\end{aligned}
$$

where $\bar{x}$ is the temporal mean of the reference variable.

In this study two datasets are used, the dependent and the independent datasets. The dependent dataset consists of the observations that were used to perform the SAFRAN analysis. The independent dataset consists of observations not used to perform the analysis. The stations were randomly assigned to each dataset. For each zone, stations located within the zone were randomly selected and added to the dependent dataset until the maximum number of stations per zone was attained. The remaining stations were assigned to the independent dataset. Thus, as the number of stations per variable is low for all the analyzed variables except precipitation (Table 2), an independent dataset was only created for precipitation. The number of dependent stations is not exactly the same for the two zone sets used, but is very close. Also, it is possible that the maps shown in this study show fewer stations than the number mentioned in Table 2. This is due to our removing stations from which $40 \%$ or more of the data are missing.

In the case of SPAN (all variables except precipitation), the metadata which lists the stations used to perform the SPAN analysis was not available to us when we performed the study, thus we didn't know which stations were dependent or independent. Thus, for these variables, SPAN is not compared to observed data.

In the case of precipitation, a common dependent observations dataset was created and, thus, we were able to compare both SAFRAN and SPAN with the same dependent and independent datasets.

SAFRAN does not use maximum and minimum temperature (Tx and Tn) to perform the analysis. Therefore, all the stations with Tx and Tn data are mostly independent. By mostly, we mean that these data have not been used to perform the analysis. However, for some stations in which the same instrument is used to determine $\mathrm{Tx}, \mathrm{Tn}$ and $\mathrm{T}$, there will be some correlation between $\mathrm{T}$ and $\mathrm{Tx}$ and $\mathrm{Tn}$.

In order to compare SAFRAN with Tx and Tn data, the maximum value of temperature among the 24 hourly values of each day was taken. We should remember here that SA- 
FRAN analyzes temperature at 0, 6, 12 and 18h, and, therefore, the hourly values come from an interpolation. As a consequence, SAFRAN is not good at determining Tx and Tn, which makes this comparison quite challenging or even unfair. SPAN was not compared with Tx and Tn data, because when we carried out the study, the hourly data was not available to us. SAFRAN is also compared with visible and infrared downward radiation. SAFRAN simulates these variables and, therefore, the observations are completely independent.

\section{Results and Discussion}

The results of our study are presented in this section. First, SAFRAN is compared with dependent stations (5.1), and then SAFRAN and SPAN are validated with independent data (5.2). Finally, the effects that the SAFRAN zones have on the resulting analysis are described (5.3).

\subsection{Comparison with Dependent Observations}

The analyzed values of the variables are compared with the observations used to run the SAFRAN analysis. Table 3 shows the bias and the RMSD of each product for each variable. The table shows the results of SAFRAN (for each one of the four possible configurations), the results of SPAN (precipitation only, see Section 3.2.) and those of HIRLAM. It is obvious that SAFRAN and SPAN will be better than HIRLAM - however, the values of the model are added to show the benefit of using an analysis system instead of data coming from an operational meteorological model.

Table 3. Mean Bias (analysis - observations) and RMSD Calculated for Dependent Stations

\begin{tabular}{lllllll}
\hline & $\mathrm{SF}_{\mathrm{m}}^{\mathrm{o}}$ & $\mathrm{SF}_{\mathrm{b}}^{\mathrm{o}}$ & $\mathrm{SF}_{\mathrm{m}}^{\mathrm{g}}$ & $\mathrm{SF}_{\mathrm{b}}^{\mathrm{g}}$ & $\mathrm{SP}$ & $\mathrm{HIR}$ \\
\hline $\mathrm{T}\left({ }^{\circ} \mathrm{C}\right)$ & 0.0 & 0.0 & -0.2 & -0.2 & - & -0.8 \\
$\mathrm{~W}\left(\mathrm{~m} \mathrm{~s}^{-1}\right)$ & -0.2 & -0.3 & -0.2 & -0.3 & - & 0.5 \\
$\mathrm{HR}(\mathrm{pp})$ & 0.3 & 0.4 & 0.1 & 0.2 & - & -0.4 \\
$\mathrm{~N}(\mathrm{oktas})$ & -1.5 & -1.2 & -1.4 & -1.2 & - & -1.0 \\
$\mathrm{P}\left(\mathrm{mm} \cdot \mathrm{d}^{-1}\right)$ & -0.1 & -0.1 & 0.0 & 0.0 & 0.1 & 0.2 \\
\hline & \multicolumn{7}{c}{$\mathrm{RMSD}$} \\
\hline $\mathrm{T}\left({ }^{\circ} \mathrm{C}\right)$ & 1.0 & 1.5 & 1.4 & 1.6 & - & 2.2 \\
$\mathrm{~W}\left(\mathrm{~m} \cdot \mathrm{s}^{-1}\right)$ & 1.2 & 1.6 & 1.3 & 1.5 & - & 2.0 \\
$\mathrm{HR}(\mathrm{p} . \mathrm{p})$. & 7.8 & 9.3 & 8.6 & 8.7 & - & 12.6 \\
$\mathrm{~N}(\mathrm{oktas})$ & 3.0 & 3.0 & 3.0 & 3.0 & - & 3.2 \\
$\mathrm{P}\left(\mathrm{mm} \cdot \mathrm{d}^{-1}\right)$ & 3.2 & 3.4 & 3.2 & 3.5 & 2.9 & 6.8 \\
\hline
\end{tabular}

*The differences in Relative Humidity are expressed in percentage points (pp).

\subsubsection{Temperature, Wind Speed and Relative Humidity}

Comparing columns $S F_{m}^{o}$ and $S F_{m}^{g}$ of Table 3 will show us the difference between the results obtained before and after the spatial interpolation to a regular grid. Comparing these two columns, it can be seen that in most cases the difference is small. Temperature is the variable most negatively affected by the spatial interpolation. Curiously, this interpolation would benefit relative humidity (which is not independent from temperature). If SAFRAN's biases are compared to HIRL-
AM's, it can be seen that SAFRAN is always better than HIRLAM, except for the cloudiness variable. If the RSMDs are compared, it will be seen that SAFRAN is always better than HIRLAM. Looking at Table 3, the negative bias of SAFRAN's wind speed is also clear when compared with dependent stations - a known problem (Quintana-Seguí et al., 2008) - but not necessarily so when compared with independent ones (Vidal et al., 2010). This bias is constant at every hour of analysis and also throughout the year. However, even with this systematic bias, SAFRAN's wind variable is more accurate than HIRLAM's. Looking at the RMSDs for the same columns, it can be seen that the interpolation degrades the values of temperature, wind and relative humidity, as was expected.

The yearly cycles at the monthly step were also studied (not shown). The cycles of the RMSD of temperature and relative humidity of both $S F_{m}^{g}$ and HIR are very stable throughout the year for both variables. The bias of $S F_{m}^{o}$ relative humidity is negative during the fall and positive during the rest of the year. The bias of temperature is stable throughout the year. $S F_{m}^{o}$ 's wind shows the characteristic negative bias during the whole year, with no seasonal difference. HIR's wind shows a positive bias which is larger than that of $S F_{m}^{o}$.

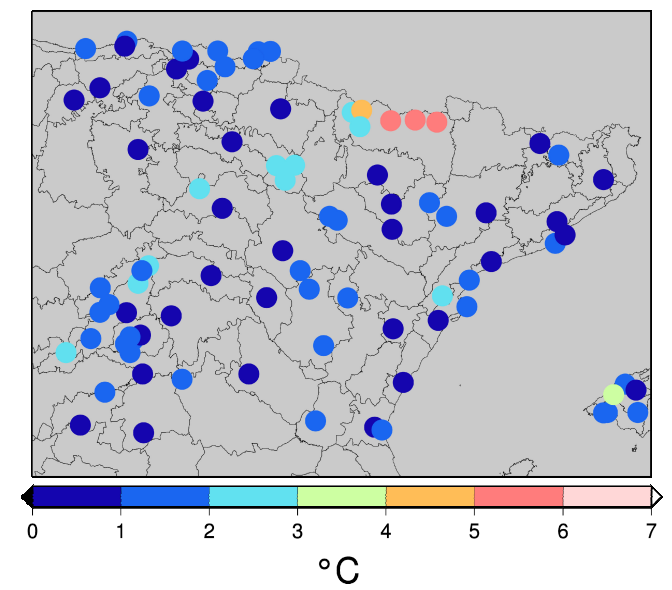

Figure 2. RMSD of mean annual temperature $\left({ }^{\circ} \mathrm{C}\right)$ between SAFRAN $\left(S F_{m}^{g}\right)$ and the dependent stations.

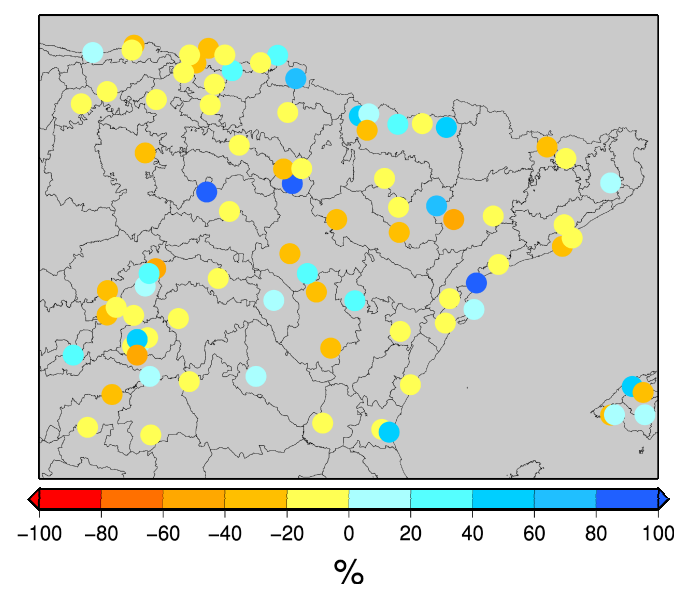

Figure 3. Relative bias of mean annual wind speed (\%) between SAFRAN $\left(S F_{m}^{g}\right)$ and the dependent stations. 
Spatially, the RMSDs between the analysis and the dependent observations of temperature are larger in the central Pyrenees, where the highest mountains are located, as can seen in Figure 2. The biases are also high and negative in the Pyrenees, but in the rest of the region the results are quite homogeneous. The amplification of the errors on the relief is also true for wind and relative humidity (especially in winter). The wind maps show that for this variable the errors are quite heterogeneous. In fact, even though in most stations the bias is negative, numerous stations with a positive bias can also be found (Figure 3). For the other variables, away from the most marked relief, the RMSDs are quite homogeneous in space and the biases do not have significant patterns. An important result to mention is that, locally, the errors can be very high. For example, there are stations with biases of temperature above $-4{ }^{\circ} \mathrm{C}$ or wind speed biases of more than $140 \%$. As a consequence, although the analysis provides good results in general, at some specific locations the errors are very high. Therefore, any user of SAFRAN data must first verify the quality of the data in the context of the specific application.

\subsubsection{Precipitation}

As in the previous section, we first look at columns $S F_{m}^{o}$ and $S F_{m}^{g}$ of Table 3. This shows the difference between the results obtained before and after performing the spatial interpolation to a regular grid. For precipitation, this has an effect on the bias, whose absolute value decreases after the interpolation. This must not be looked on as an improvement due to the interpolation, though, but as a compensation of errors. The sign of the bias is changed. What is more important is that the $R M S D$ is not modified for this variable.

For this variable, we can compare SAFRAN and SPAN (see columns $S F_{m}^{g}$ and SP in Table 3): SPAN is a little more biased than SAFRAN, although its RMSD is better ( $9 \%$ smaller).

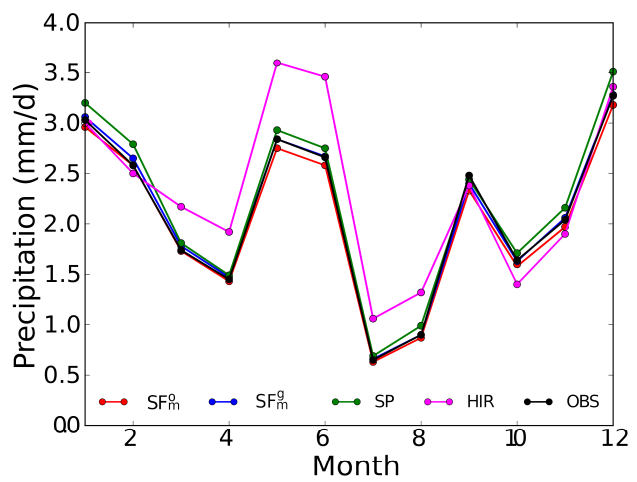

Figure 4. Spatially aggregated monthly mean precipitation $\left(\mathrm{mm} \mathrm{d}^{-1}\right)$. SAFRAN $\left(S F_{m}^{0}\right.$ and $\left.S F_{m}^{g}\right)$, SPAN (SP) and HIRLAM (HIR) are compared with the dependent observations (OBS).

SAFRAN's and SPAN's monthly precipitation cycles are very close and quite different to HIRLAM's (Figure 4). The monthly biases and RMSDs (not shown) are very close throughout the year for both. Thus, both products are similar in this respect.
The maps of the bias and RMSD of precipitation were also analyzed, but they are not shown because similar maps, calculated with independent data, are presented in Section 0. The spatial structure of the bias is very variable from one month to another, which is due to the fact that we work with one year of data and therefore individual events heavily influence the final result. Thus, the value of such an analysis is limited. However, the maps show that the relative $R M S D$ is lower in the Atlantic area, which was expected due to the more homogeneous properties of rainfall there, compared with the more variable Mediterranean area.

\subsubsection{Cloudiness and Radiation}

Figure 5 and Table 3 show that SAFRAN's cloudiness analysis is not good - the cycle is inverted and the bias is negative. In fact, the RMSD is very high. Thus, the analysis of this variable is not reliable. The larger errors are on the northwestern coast of the study area (not shown). The errors are also larger in winter, which is expected as this is the period of the year with more clouds (not shown). These problems will affect the quality of the downward radiation.

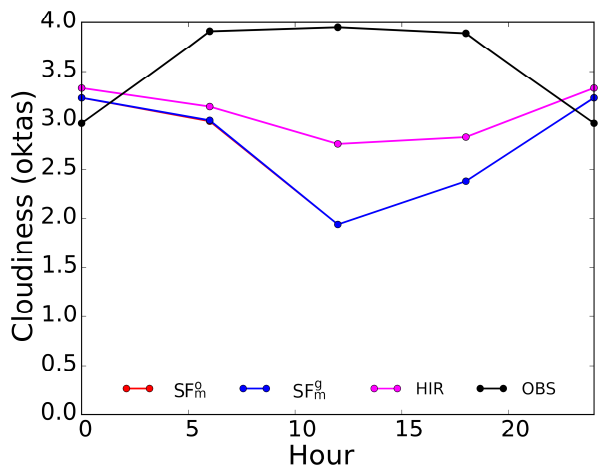

Figure 5. Spatially aggregated hourly mean cloudiness (oktas). SAFRAN ( $S F_{m}^{0}$ and $S F_{m}^{g}$ ) and HIRLAM (HIR) are compared with the dependent observations (OBS).

\subsection{Validation with Independent Observations}

In this section, the results are compared with independent data. This has been done for precipitation (SAFRAN and SPAN), maximum and minimum temperature (SAFRAN), and downward radiation, both visible and infrared (SAFRAN). The results are summarized in Table 4.

\subsubsection{Temperature}

Table 4 shows that the biases of Tx and Tn are large and close to those found in France by Vidal et al. (2010). Figure 6 shows that the biases are more important in summer. Vidal et al. (2010) also found a similar seasonal cycle in France but, however, in north-east Spain the bias is lower for Tn, which might be due to differences in the diurnal cycle. The magnitude of these errors was expected, because this variable was approximated selecting the highest/lowest values of the 24 hourly values, which is an imprecise method to derive a Tx/ Tn from an hourly dataset. Furthermore, SAFRAN derives the 
hourly values by fitting a sinusoidal curve to the observations at $0,6,12$ and 18 UTC. We think it is important to show this result because this will affect, for example, LSM simulations in situations where the temperature reaches thresholds, such as freezing, that affect non linearly the simulations.

Table 4. Mean Bias (analysis - observations) and RMSD Calculated for Independent Stations

\begin{tabular}{lcccc}
\hline Variable & $\mathrm{SF}_{\mathrm{m}}^{\mathrm{o}}$ & $\mathrm{SF}_{\mathrm{m}}^{\mathrm{g}}$ & $\mathrm{SPAN}$ & $\mathrm{HIR}$ \\
\hline \multicolumn{5}{c}{$\mathrm{Bias}$} \\
\hline $\mathrm{P}\left(\mathrm{mm} \cdot \mathrm{d}^{-1}\right)$ & -0.0 & 0.0 & 0.1 & 0.2 \\
$\mathrm{Tx}\left({ }^{\circ} \mathrm{C}\right)$ & -1.0 & -1.6 & & \\
$\operatorname{Tn}\left({ }^{\circ} \mathrm{C}\right)$ & 0.8 & 0.5 & & \\
$\mathrm{Sol}\left(\mathrm{W} \cdot \mathrm{m}^{-2}\right)$ & & 10 & \\
$\mathrm{IR}\left(\mathrm{W} \cdot \mathrm{m}^{-2}\right)$ & & -12 & \\
\hline & \multicolumn{5}{c}{$\mathrm{RMSE}$} \\
\hline $\mathrm{P}\left(\mathrm{mm} \cdot \mathrm{d}^{-1}\right)$ & 3.6 & 3.6 & 3.2 & \\
$\mathrm{Tx}\left({ }^{\circ} \mathrm{C}\right)$ & 2.3 & 2.7 & & \\
$\operatorname{Tn}\left({ }^{\circ} \mathrm{C}\right)$ & 2.3 & 2.2 & \\
$\mathrm{Sol}\left(\mathrm{W} \cdot \mathrm{m}^{-2}\right)$ & & 114 & \\
$\mathrm{IR}\left(\mathrm{W} \cdot \mathrm{m}^{-2}\right)$ & & 33 & \\
\hline
\end{tabular}

\subsubsection{Precipitation}

Concerning precipitation, Table 4 shows that the bias of this variable is very close to the bias obtained when comparing with dependent observations (Table 3). Furthermore, the $R M S E$ of the independent stations is higher, as expected (compare with Table 3), but it remains reasonable in both cases. This result is very positive, as it shows that both SAFRAN and SPAN correctly represent precipitation, which is always a challenging variable to analyze. Figure 7 shows that SAFRAN and SPAN are close and that they are much better than HIRLAM. HIRLAM largely overestimates precipitation from March to August. The spatial structure of the errors was also studied (Figure 8). The maps for SAFRAN and SPAN present similar features. The errors are larger in the interior of the region, which is semiarid, and smaller in the Atlantic area of the north-west of the region. In general, the biases are not larger than $25 \%$, with some exceptions. However, we must bear in mind that these results are affected by a small number of events as we work with very short time series. In fact, (Vidal et al., 2010) found smaller RMSEs in France. This could be linked to different patterns of precipitation or to the short time series we are using. HIRLAM's errors are much larger, as expected. Thus, compared to the outputs of an operational meteorological model, both analyses are a great improvement, even though SPAN is slightly better than SAFRAN.

(a) $T x$

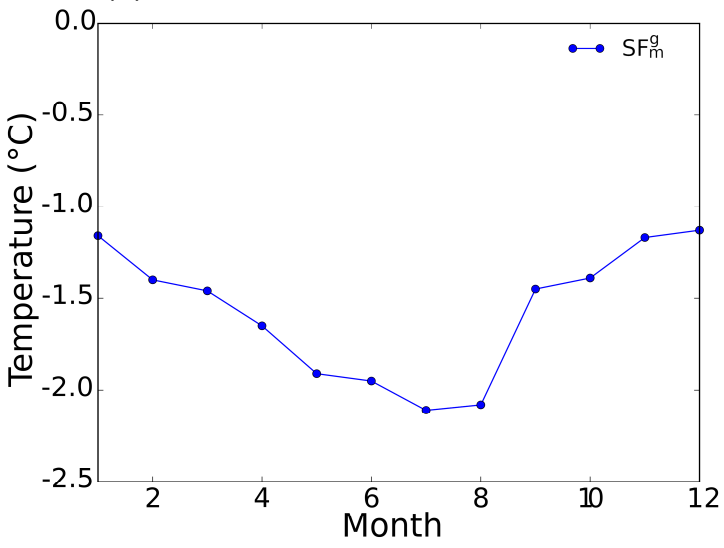

(b) $\mathrm{Tn}$

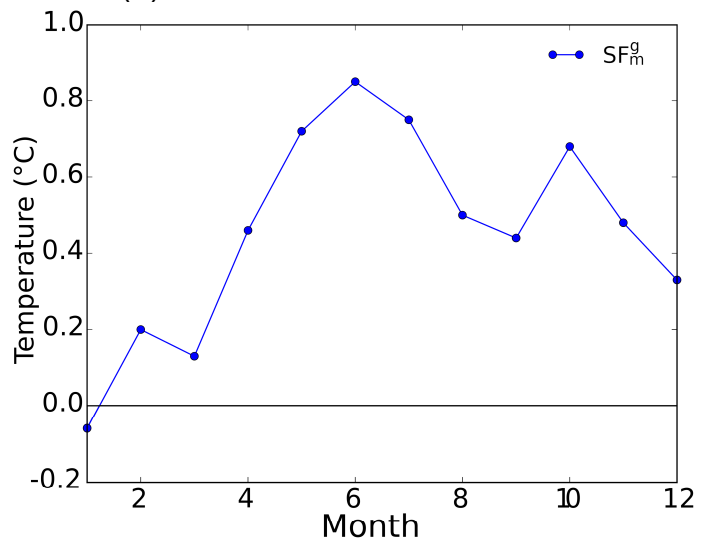

Figure 6. Spatially aggregated monthly mean bias of Tx and Tn $\left({ }^{\circ} \mathrm{C}\right)$. SAFRAN $\left(S F_{m}^{g}\right)$ is compared to the independent observations. (a) Mean

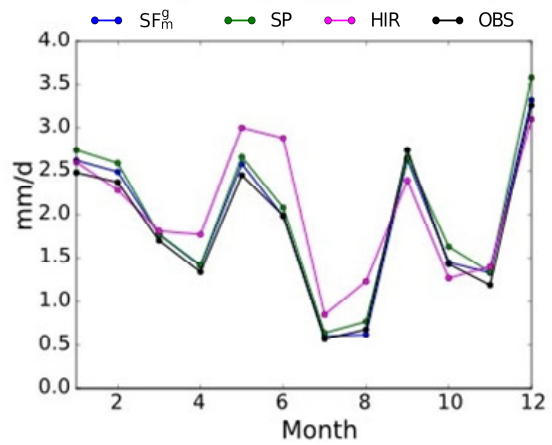

(b) Bias

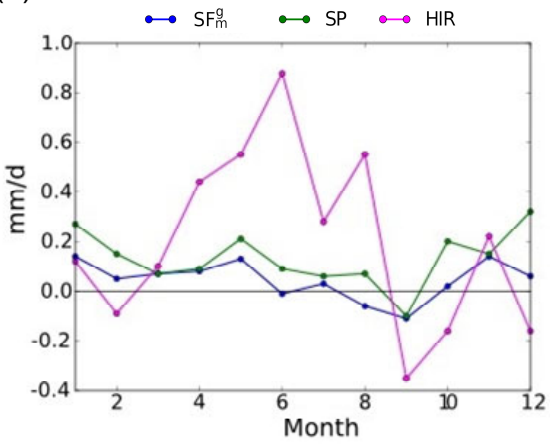

(c) RMSE

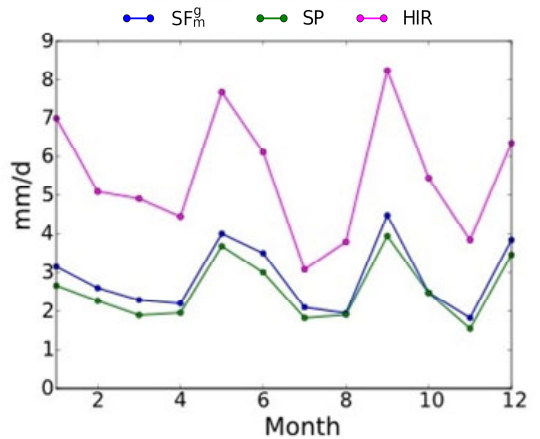

Figure 7. Spatially aggregated monthly mean, bias and RMSE of precipitation $\left(\mathrm{mm} \mathrm{d}^{-1}\right)$. SAFRAN ( $\left.S F_{m}^{g}\right), \operatorname{SPAN}(\mathrm{SP})$ and HIRLAM (HIR) are compared with the independent observations (OBS). 
(a) $B S F_{m}^{g}$

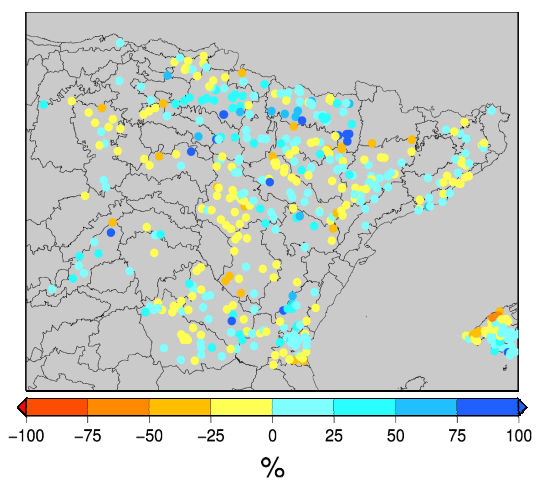

(d) $R M S E_{r} S F_{m}^{g}$

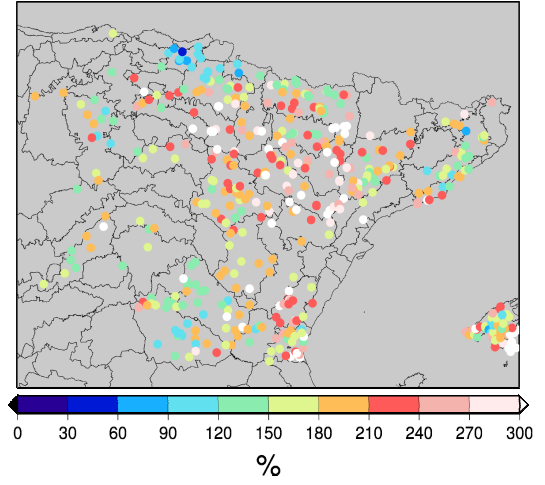

(b) $B, S P$

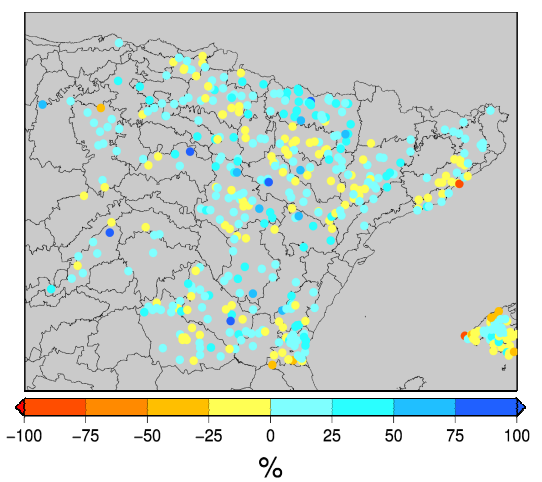

(e) RMSE, SP

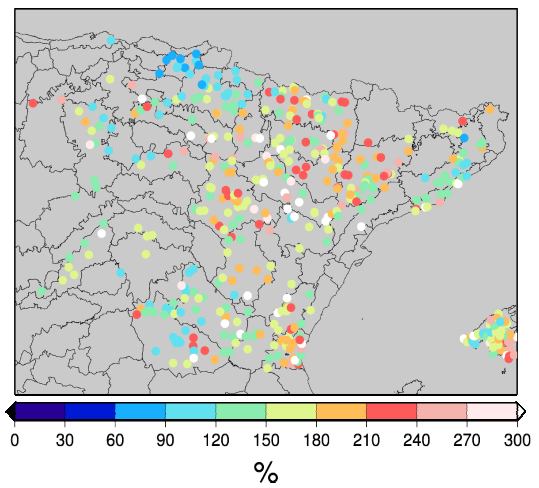

(c) $B_{r} H I R$

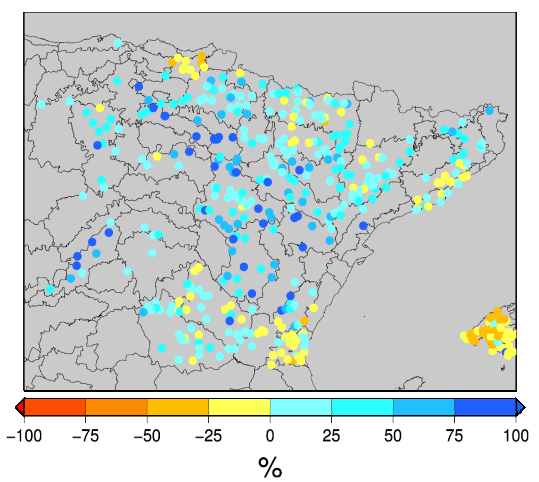

(f) $R M S E_{r} H I R$

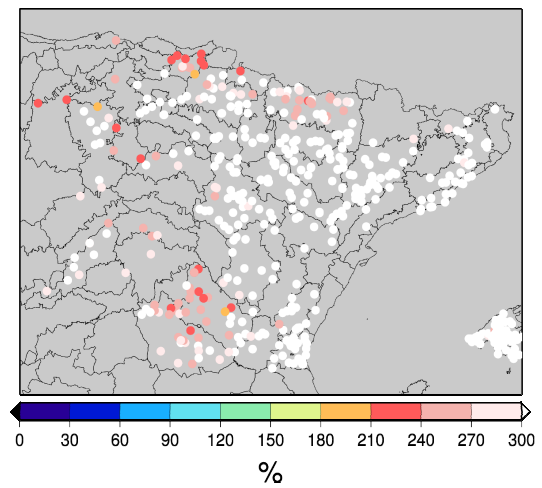

Figure 8. Mean relative bias $\left(\mathrm{B}_{\mathrm{r}}\right)$ and RMSEr of precipitation (\%). SAFRAN ( $\left.S F_{m}^{g}\right)$, SPAN (SP) and HIRLAM (HIR) are compared with the independent observations (OBS).

\subsubsection{Radiation}

Table 4 also shows the annual mean bias and RMSE for the total visible radiation (Sol) and downward infrared radiation (IR). In this case, the values of $S F_{m}^{g}$ are shown, as it is the final product that users will use. The results are close to those obtained in France (Quintana-Seguí et al., 2008). There is a small overestimation of visible radiation and an underestimation of infrared radiation, which is coherent with the underestimation of cloudiness seen previously. Figure 9 shows that the model correctly reproduces the annual cycle of these variables. The RMSE of visible solar radiation is higher in summer, when there is more radiation, but the RMSEr is higher in winter. The RMSE and RMSEr of infrared radiation are higher in winter too. This is probably due to the errors related to the analysis of cloudiness.

\subsection{The Impact of Climatically Homogeneous Zones}

The use of climatically homogeneous zones is an important feature of SAFRAN. Table 3 allows us to compare the results obtained using AEMET's meteorological warning zones $(m)$ and river basins $(b)$ before carrying out the spatial interpolation $\left(S F_{m}^{o}\right.$ vs $\left.S F_{b}^{o}\right)$ and after $\left(S F_{m}^{g}\right.$ vs $\left.S F_{b}^{g}\right)$. The maps of the zones can be seen in Figure 1. Before the spatial interpolation, the biases are very close for all the variables. However, the $R M S D s$ obtained when using river basins are higher than those obtained using the meteorological warning zones. Thus, the meteorological warning zones, which were defined (a) Visible Solar Radiation

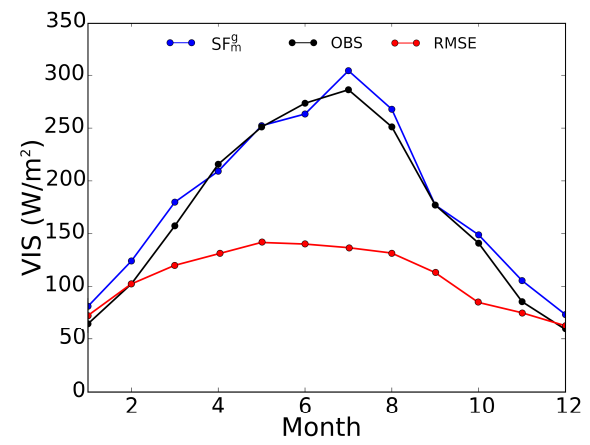

(b) Infrared Radiation

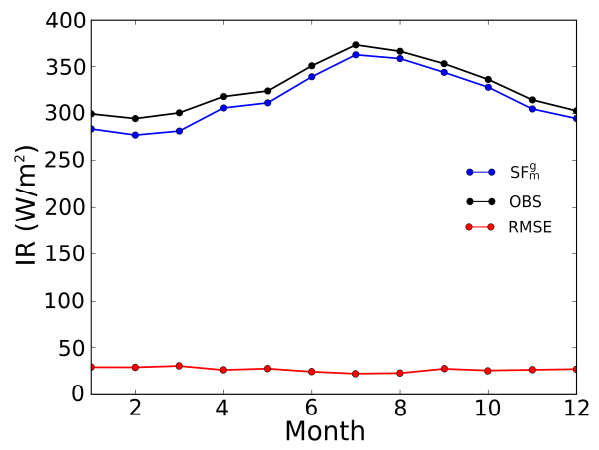

Figure 9. Spatially aggregated monthly cycle and RMSE of downward visible solar and infrared radiation $\left(\mathrm{W} \mathrm{m}^{-2}\right)$. SAFRAN ( $S F_{m}^{g}$, in blue) is compared with independent observations (OBS, in green). The RMSE is shown in red. 
using expert knowledge gathered by AEMET's meteorologists, are climatically more homogeneous than the river basins. However, after the spatial interpolation to the grid, the differences in $R M S D$ are smaller. The errors introduced by spatial interpolation partially mask the errors due to the zones. Thus, the conclusion is that, provided that the chosen zone set has a climatological sense, the impact of the zone set used on biases and RMSDs is not very relevant for the end users of SAFRAN, as they will be using the interpolated product. As a consequence, in the previous sections most results were only shown for one zone set (meteorological warning zones).

In order to further inspect the effect of the zones, SAFRAN and SPAN were compared for some variables. Figure 10 shows that the spatial field of SAFRAN temperature is smooth (first pane), but some spatial structures appear when the difference between SAFRAN and SPAN is calculated (second pane). Figure 11 shows more clearly the spatial discontinuities introduced by the zones. The first pane, which corresponds to

(a) $\mathrm{SF}_{\mathrm{m}}^{\mathrm{g}}$

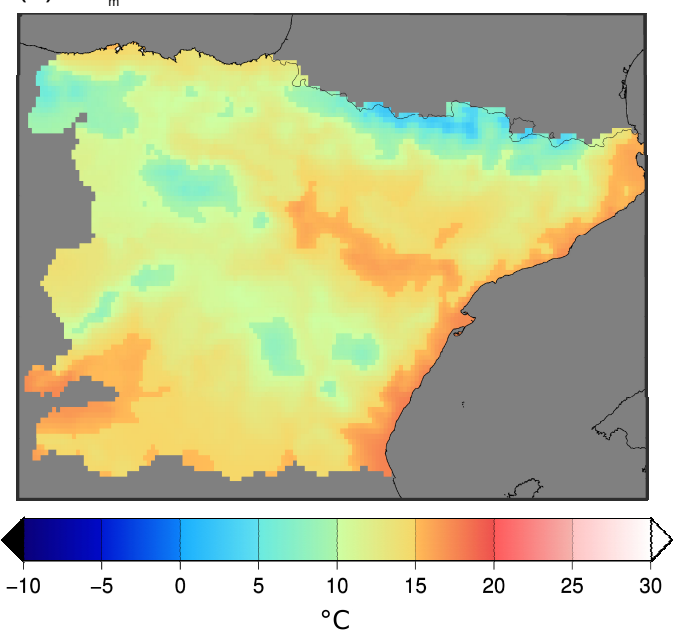

the mean annual wind field of SAFRAN, reveals the underlying structure of the zones. On the other hand, the second pane, which corresponds to SPAN, is smoother. In fact, wind is the variable that shows the effect of the zones most drastically. In Figure 11 there is a zone that is very distinctive, compared with the surrounding zones. It has a mean wind speed higher than $5 \mathrm{~m} \cdot \mathrm{s}^{-1}$ (orange), while the surrounding ones have wind speeds lower than $5 \mathrm{~m} \cdot \mathrm{s}^{-1}$ (green and blue). Figure 3 tells us that that the zone has three stations, one with a positive bias and two others with a negative bias. This means that in that zone there is one station with a local behavior different to the behavior of the other two stations located in the same zone. The zone is very elongated and the stations are located on the eastern side of the zone, and, thus, these are certainly not representative of what might happen on the other side of the zone. This shows that the concept of climatologically homo- geneous zones is ill suited for the analysis of wind speed, as wind is often severely affected by local effects (orography, breezes,

(b) $\operatorname{Diff}\left(\mathrm{SF}_{\mathrm{m}}^{\mathrm{g}}-\mathrm{SP}\right)$

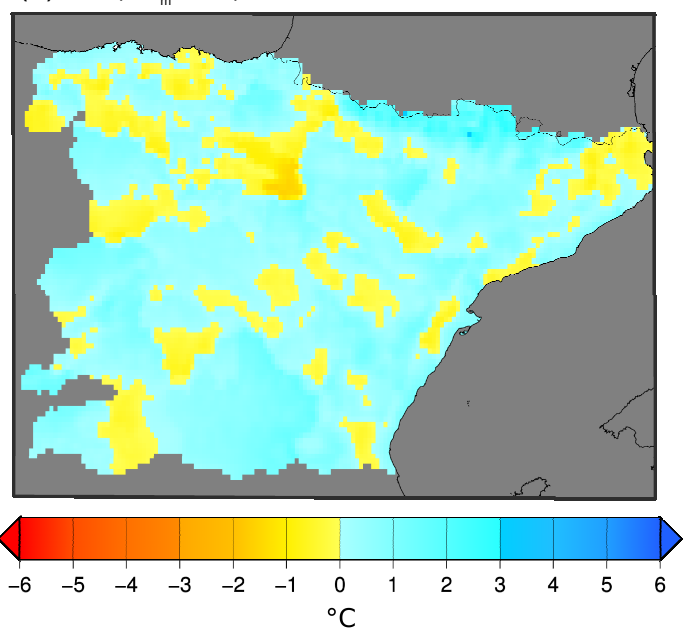

Figure 10. First pane: annual mean SAFRAN $\left(S F_{m}^{g}\right)$ temperature $\left({ }^{\circ} \mathrm{C}\right)$. Second pane: difference of annual mean temperature $\left({ }^{\circ} \mathrm{C}\right)$, SAFRAN ( $\left.S F_{m}^{g}\right)$ minus SPAN (SP).

(a) $\mathrm{SF}_{\mathrm{m}}^{\mathrm{g}}$

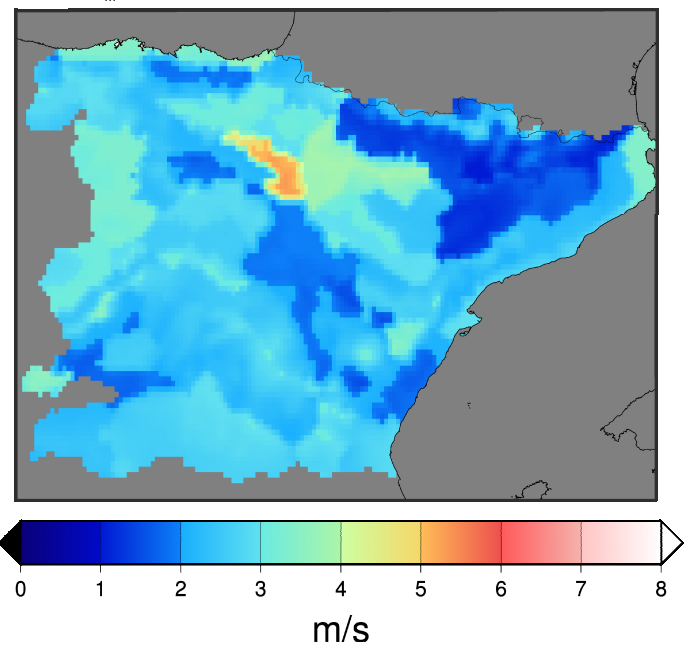

(b) SP

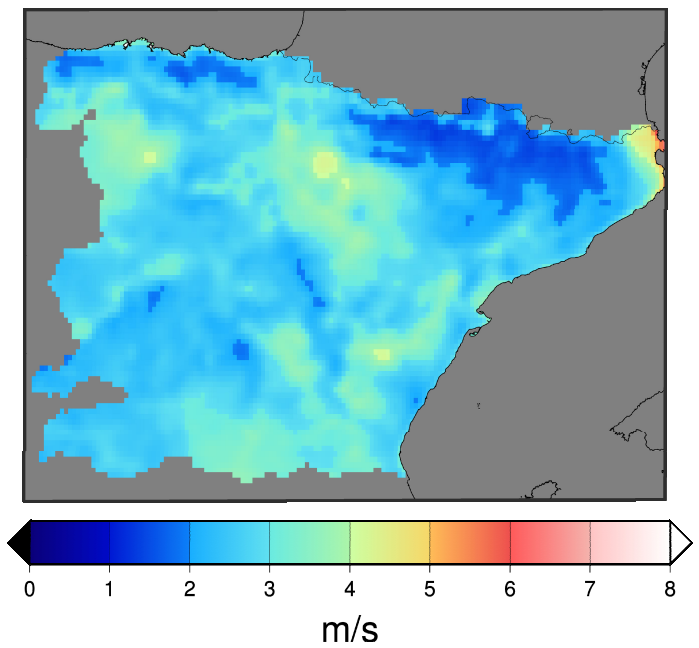

Figure 11. Annual mean wind speed $\left(\mathrm{m} \mathrm{s}^{-1}\right)$. First pane: SAFRAN $\left(S F_{m}^{g}\right)$. Second pane: SPAN (SP). 
etc.) and thus the stations do not correctly represent their zones. For precipitation (Figure 12) these effects can have important consequences too as, for instance, some flat areas close to the relief, which are included in the same zone of the relief, may receive too much water and this will have an impact on the hydrological simulations forced by SAFRAN. Figure 12 also compares the fields obtained using meteorological warning zones (Figure 12.a) and river basins (Figure 12.b). The comparison shows that the impacts of the zone set can have important local effects. Thus, the concept of homogeneous zones works well for variables with a high spatial homogeneity, like temperature, but the more spatially heterogeneous the variable is, the more problems we find related to zones. Wind speed is probably the most affected variable, but precipitation also suffers from this problem.

\section{Conclusions}

The objective of this study was to validate SAFRAN and SPAN in Spain. It was shown that SAFRAN's scores in Spain are very close to those of SAFRAN in France and to those of SPAN. Thus, both SAFRAN and SPAN can be used in Spain for the same applications for which SAFRAN is currently and successfully used in France.

Two kinds of climatically homogeneous zones were used: one based on AEMET's meteorological warning zones and another one based on river basins. SAFRAN performed slightly better when the warning zones were used, and so this is a validation of this climatological division of Spain. The difference is small, though, and, therefore, it was shown that SAFRAN is not very sensitive to the zones used, which allows us to use these, or any other more convenient zones in future studies, provided that the zones are reasonably related to climatology.

Of course, the problems that SAFRAN has in France also persist in Spain. The fields are not very realistic, as they are discontinuous at the zone borders - a problem which severely affects the wind and precipitation variables. Some further optimization of the zones could help to minimize these pro- blems, even though SAFRAN is not very sensitive to these zones as we have seen. Smaller zones would probably help improve the results for precipitation, as there is a very dense observation network, and wind speed might be improved too. Furthermore, the number of stations that are analyzed in each zone could be increased, which would probably have a positive impact on precipitation values. Finally, the methodology could be improved by removing from the independent dataset stations that are not representative of their zones, because they are too affected by purely local effects.

In order to improve the quality of the wind analysis, it would be necessary to better use the high resolution fields of HIRLAM-HNR. At present, the analysis degrades the first guess (HIRLAM-HNR) to the scale of the zone, losing the high resolution information of the meteorological model.

The analysis of cloudiness is not good, which will affect the results of the radiation scheme. In the future, this issue must be further investigated. For cloudiness, the first guess is deduced from the humidity profile of the model and its quality is probably too low. Thus, any improvement here would involve using the cloudiness estimated by the meteorological model itself. However, cloudiness is mainly analyzed in order to calculate radiation. An improvement would be to directly use the modelled HIRLAM-HNR radiation, instead of the analyzed one.

As expected, SAFRAN and SPAN work better for the plains, compared with the mountain areas where they differ more, both between themselves and in comparison with observations. This can be problematic for hydrological applications, especially in the Ebro river basin, as most of the runoff is generated over the Pyrenees. However, it is expected that SAFRAN's precipitation fields will be better than those of other products such as E-OBS or Spain02. This aspect should be further evaluated in the future.

Within the context of HyMeX and eartH2Observe, our long-term aim is to build a hydrometeorological suite, similar to the French SIM (Habets et al., 2008), which uses SAFRAN and the ISBA land-surface model (Noilhan and Planton, 1989; Noilhan and Mahfouf, 1996), currently integrated in the SUR- (a) $S F_{m}^{g}$

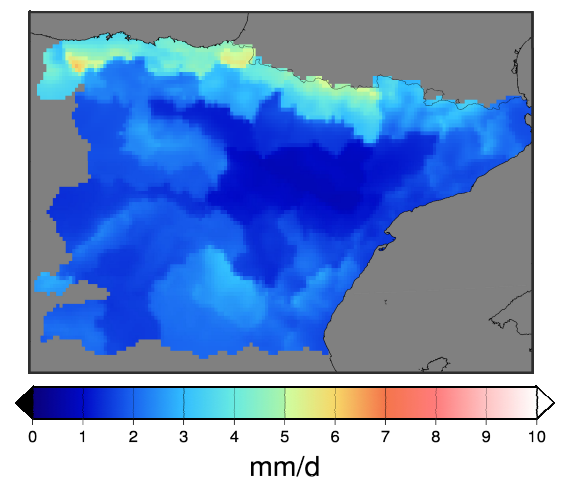

(b) $\mathrm{SF}_{\mathrm{b}}^{\mathrm{g}}$

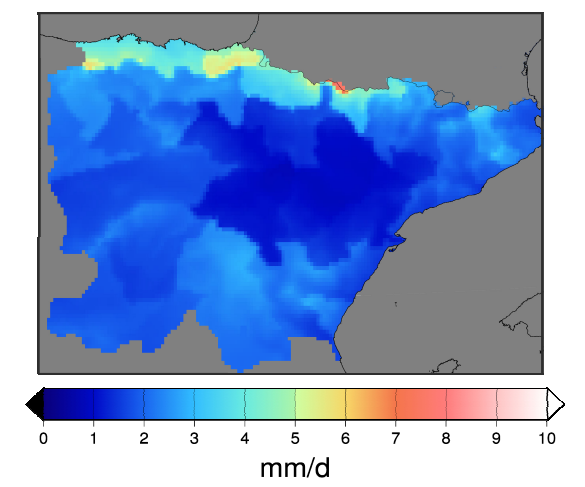

(c) SP

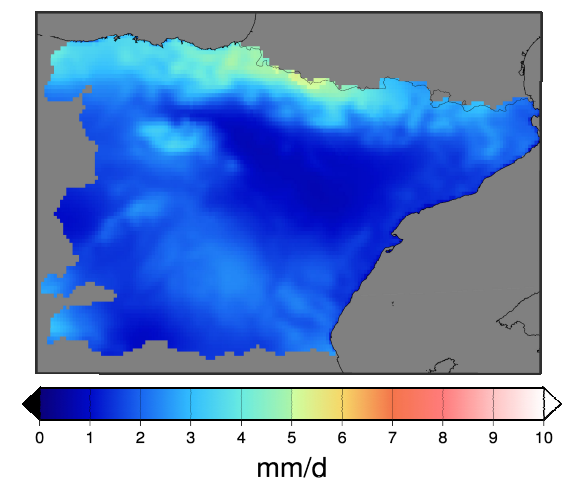

Figure 12. Annual mean precipitation $\left(\mathrm{mm} \mathrm{d}^{-1}\right)$. First pane: SAFRAN $\left(S F_{m}^{g}\right)$. Second pane: SAFRAN $\left(S F_{b}^{g}\right)$. Third pane: SPAN (SP). 
FEX platform (Masson et al., 2013), as the land surface scheme. This will allow us to study several aspects of the hydrological cycle of the Ebro river basin and other areas of Spain. Furthermore, when extended to a longer period, SAFRAN will be very useful in order to validate, bias correct and downscale Regional Climate Models (RCMs), which will improve our capacity to study the impacts of climate change on this area. The extension of the SAFRAN database to a longer period will also allow us to further validate our analysis and thus overcome some of the limitations of this study, which is based on a single year of data.

Finally, we hope that the work done by other projects, such as EURO4M, on products such as MESCAN (Soci and Bazile, 2013), will derive in a European-scale high quality and high resolution analysis product which should avoid the extra work of creating products for specific regions. Until this is a reality, products such as the implementation presented in this article are very important to foster research in land - surface related topics, which require good quality meteorological gridded datasets.

Acknowledgments. We want to thank Beatriz Navascués, Alberto Cansado, José A. García Moya and Isabel Martínez, from AEMET, for their useful comments and suggestions concerning the SPAN related work of this study. We also want to thank the anonymous reviewers, whose thoughtful comments helped us improve important aspects of this paper. This work is a contribution to the HyMeX (Hydrologial cycle in the Mediterranean experiment) program (http:// www.hymex.org). This is a contribution to the FP7 eartH2Observe project (http://www.earth2observer.eu). This project has received funding from the European Union's Seventh Program for research, technological development and demonstration under grant agreement No 603608 .

\section{References}

AEMET (2011). Iberian Climate Atlas, Ministerio de Medio Ambiente y Medio Rural y Marino., Madrid [online]. Available from: http://www.aemet.es/documentos/es/conocermas/publicaciones/Atl as-climatologico/Atlas.pdf.

Albergel, C., Rüdiger, C., Pellarin, T., Calvet, J.-C., Fritz, N., Froissard, F., Suquia, D., Petitpa, A., Piguet, B., and Martin, E. (2008). From near-surface to root-zone soil moisture using an exponential filter: an assessment of the method based on in-situ observations and model simulations. Hydrol. Earth Syst. Sci., 12(6), 1323-1337. http://dx.doi.org/10.5194/hess-12-132 3-2008

Van den Besselaar, E.J.M., Haylock, M.R., van der Schrier, G., and Klein Tank, A.M.G. (2011). A European daily high-resolution observational gridded data set of sea level pressure. J. Geophys. Res., 116(D11), D11110. http://dx.doi.org/10.1029/ 2010JD015468

Boé, J., Terray, L., Martin, E., and Habets, F. (2009). Projected changes in components of the hydrological cycle in French river basins during the 21st century. Water Resour. Res., 45(8), 84268426. http://dx.doi.org/10.1029/2008WR007437

Bouilloud, L., Martin, E., Habets, F., Boone, A., Le Moigne, P., Livet, J., Marchetti, M., Foidart, A., Franchistéguy, L., Morel, S., Noilhan, J., and Pettré, P. (2009). Road surface condition forecasting in France. J. Appl. Meteorol. Climatol., 48(12), 2513-2527. http:// dx.doi.org/10.1175/2009JAMC1900.1

Brochero, D., Anctil, F., and Gagné, C. (2011). Simplifying a hydrological ensemble prediction system with a backward greedy selection of members-Part 1: Optimization criteria. Hydrol. Earth Syst. Sci., 15(11), 3307-3325. http://dx.doi.org/10.5194/hess-15-33072011
Bru, D., Ramette, A., Saby, N.P.A., Dequiedt, S., Ranjard, L., Jolivet, C., Arrouays, D., and Philippot, L. (2011). Determinants of the distribution of nitrogen-cycling microbial communities at the landscape scale. ISME J., 5(3), 532-542. http://dx.doi.org/10. 1038/ismej.2010.130

Brun, E., Martin, E., Simon, V., Gendre, C., and Coleou, C. (1989). An energy and mass model of snow cover suitable for operational avalanche forecasting. J. Glaciol., 35(121), 333-342.

Brut, A., Rüdiger, C., Lafont, S., et al. (2009). Modelling LAI at a regional scale with ISBA-A-gs: comparison with satellite-derived LAI over southwestern France. Biogeosciences, 6(8), 1389-1404. http://dx.doi.org/10.5194/bg-6-1389-2009

Bürger, C.M., Kolditz, O., Fowler, H.J., and Blenkinsop, S. (2007). Future climate scenarios and rainfall-runoff modelling in the Upper Gallego catchment (Spain). Environ. Pollut., 148 (3), 842-854. http://dx.doi.org/10.1016/j.envpol.2007.02.002

Calvet, J. C., Lafont, S., Cloppet, E., Souverain, F., Badeau, V., and Le Bas, C. (2012). Use of agricultural statistics to verify the interannual variability in land surface models: a case study over France with ISBA-A-gs. Geosci. Model Dev., 5(1), 37-54, http://dx.doi. org/10.5194/gmd-5-37-2012

Cansado, A. (2002). Ampliando el análisis de superficie en HIRLAM. Análisis de la presión a nivel del mar., Agencia Estatal de Meteorología, Madrid.

Cansado, A. (2003). Análisis bivariante del viento a $10 \mathrm{~m}$ por interpolación óptima, Agencia Estatal de Meteorología., Madrid.

Cansado, A., Martín, C., and Navascués, B. (2004). Optimum interpolation New Snow Depth Analysis in HIRLAM. HIRLAM Newsl., (45), 248-252.

Céron, J.P., Tanguy, G., Franchistéguy, L., Martin, E., Regimbeau, F., and Vidal, J.P. (2010). Hydrological seasonal forecast over France: Feasibility and prospects. Atmos. Sci. Lett., 11(2), 78-82. http:// dx.doi.org/10.1002/asl.256

Claverie, M., Demarez, V., Duchemin, B., et al. (2012). Maize and sunflower biomass estimation in southwest France using high spatial and temporal resolution remote sensing data. Remote Sens. Environ., 124, 844-857. http://dx.doi.org/10.101 6/j.rse.2012.04.005, 2012.

Dee, D.P., Uppala, S.M., Simmons, A.J., et al. (2011). The ERAInterim reanalysis: configuration and performance of the data assimilation system. Q. J. R. Meteorol. Soc., 137(656), 553-597. http://dx.doi.org/10.1002/qj. 828

Dequiedt, S., Saby, N.P.A., Lelievre, M., et al. (2011). Biogeographical patterns of soil molecular microbial biomass as influenced by soil characteristics and management. Glob. Ecol. Biogeogr., 20(4), 641-652. http://dx.doi.org/10.1111/j.1466-8238.2010. 00628.x

Diffenbaugh, N.S. and Giorgi, F. (2012). Climate change hots- pots in the CMIP5 global climate model ensemble. Clim. Change, 114, 813-822. http://dx.doi.org/10.1007/s10584-012-0570-x

Draper, C., Mahfouf, J.F., Calvet, J.C., Martin, E., and Wagner, W. (2011). Assimilation of ASCAT near-surface soil moisture into the SIM hydrological model over France. Hydrol. Earth Syst. Sci., 15(12), 3829-3841. http://dx.doi.org/10.5194/hess-15-3829-2011

Draper, C.S., Mahfouf, J.F., and Walker, J.P. (2009). An EKF assimilation of AMSR-E soil moisture into the ISBA land surface scheme. J. Geophys. Res. Atmos., 114(D20), D20104. http://dx.doi.org/ 10.1029/2008JD011650

Drobinski, P., Ducrocq, V., Alpert, P., et al. (2013). HyMeX, a 10-year multidisciplinary program on the Mediterranean water cycle. Bull. Am. Meteorol. Soc., 95, 1063-1082. http://dx.doi. org/10.1175/BAMS-D-12-00242.1

Dünkeloh, A. and Jacobeit, J. (2003). Circulation dynamics of Mediterranean precipitation variability 1948-98. Int. J. Climatol., 23(15), 1843-1866. http://dx.doi.org/10.1002/joc.97 3 
Durand, Y. (1995). Analyse des principaux paramètres météorologiques de surface sur les massifs alpins et d'autres zones climatologiquement cohérentes. Notice scientifique et technique SAFRAN (Vol. 1).

Durand, Y., Brun, E., Merindol, L., Guyomarc'h, G., Lesaffre, B., and Martin, E. (1993). A meteorological estimation of relevant parameters for snow models. Ann. Glaciol., 18, 65-71. http:// dx.doi.org/ 10.1002/hyp.10125

Durand, Y., Giraud, G., Brun, E., Merindol, L., and Martin, E. (1999). A computer-based system simulating snowpack structures as a tool for regional avalanche forecasting. J. Glaciol., 45(151), 469-484.

Durand, Y., Laternser, M., Giraud, G., Etchevers, P., Lesaffre, B. and Mérindol, L. (2009). Reanalysis of $44 \mathrm{Yr}$ of Climate in the French Alps (1958-2002): Methodology, Model Validation, Climatology, and Trends for Air Temperature and Precipitation. J. Appl. Meteorol. Climatol., 48(3), 429-449. http://dx.doi.org/10.1175/2008 JAMC1808.1

Estrela, T., Pérez-Martin, M.A., and Vargas, E. (2012). Impacts of climate change on water resources in Spain. Hydrol. Sci. J., 57(6), 1154-1167. http://dx.doi.org/10.1080/02626667.2012.70 2213

Gandin, L.S. (1966). Objective analysis of meteorological fields. By L.S. Gandin. Translated from the Russian. Jerusalem (Israel Program for Scientific Translations), Q.J.R. Meteorol. Soc., 92(393), 447-447. http://dx.doi.org/10.1002/qj.49709239 320

Gascoin, S., Ducharne, A., Ribstein, P., Carli, M., and Habets, F. (2009). Adaptation of a catchment-based land surface model to the hydrogeological setting of the Somme River basin (France). $J$. Hydrol., 368(1-4), 105-116. http://dx.doi.org/10.1016/j.jhydrol. 2009.01.039

Habets, F., Boone, A., Champeaux, J.L., Etchevers, P., et al. (2008). The SAFRAN-ISBA-MODCOU hydrometeorological model applied over France. J. Geophys. Res. Atmos., 113, D06 113. http:// dx.doi.org/10.1029/2007JD008548

Habets, F., Gascoin, S., Korkmaz, S., et al. (2009). Multi-model comparison of a major flood in the groundwater-fed basin of the Somme River (France). Hydrol. Earth Syst. Sci. Discuss., 6(1), 6135-6180. http://dx.doi.org/10.5194/hessd-6-6135-2009

Häggmark, L., Ivarsson, K.I., Gollvik, S., and Olofsson, P.O. (2000). Mesan, an operational mesoscale analysis system. Tellus, Ser. A Dyn. Meteorol. Oceanogr., 52, 2-20. http://dx.doi.org/10.3402/ tellusa.v52i1.12250

Haylock, M.R., Hofstra, N., Klein Tank, A.M.G., Klok, E.J., Jones, P.D., and New, M. (2008). A European daily high-resolution gridded data set of surface temperature and precipitation for 1950-2006. J. Geophys. Res. Atmos., 113(D20), D20119. http:// dx.doi.org/10.1029/2008JD010201

Herrera, S., Gutiérrez, J.M., Ancell, R., Pons, M.R., Frías, M.D., and Fernández, J. (2012). Development and analysis of a 50-year high-resolution daily gridded precipitation dataset over Spain (Spain02). Int. J. Climatol., 32(1), 74-85. http://dx.doi.org/10. $1002 /$ joc. 2256

Iglesias, A., Cancelliere, A., Wilhite, D.A., Garrote, L., Cubillo, F., and Tsakiris, G. (2009). Coping with Drought Risk in Agriculture and Water Supply Systems, Springer Netherlands.

Iglesias, A., Garrote, L., Flores, F., and Moneo, M. (2007). Challenges to manage the risk of water scarcity and climate change in the Mediterranean. Water Resour. Manag., 21(5), 775-788. http://dx. doi.org/10.1007/s11269-006-9111-6

Javelle, P., Fouchier, C., Arnaud, P., and Lavabre, J. (2010). Flash flood warning at ungauged locations using radar rainfall and antecedent soil moisture estimations. J. Hydrol., 394(1-2), 267-274. http://dx.doi.org/10.1016/j.jhydrol.2010.03.032

Korkmaz, S., Ledoux, E., and Önder, H. (2009). Application of the coupled model to the Somme river basin. J. Hydrol., 366(1-4), 21-34. http://dx.doi.org/10.1016/j.jhydrol.2008.12.0 08
Lafaysse, M., Hingray, B., Etchevers, P., Martin, E., and Obled, C. (2011). Influence of spatial discretization, underground water storage and glacier melt on a physically-based hydrological model of the Upper Durance River basin. J. Hydrol., 403(1-2), 116-129. http://dx.doi.org/10.1016/j.jhydrol.2011.03. 046

Llasat, M.C., Barriendos, M., Barrera, A., and Rigo, T. (2005). Floods in Catalonia (NE Spain) since the 14th century. Clim tological and meteorological aspects from historical documentary sources and old instrumental records. J. Hydrol. 313, 32-47. http://dx.doi.org/10.1016/j.jhydrol.2005.02.004

Llasat, M.C., Llasat-Botija, M., and López, L. (2009). A press database on natural risks and its application in the study of floods in Northeastern Spain. Nat. Hazards Earth Syst. Sci., 9, 2049-2061. http://dx.doi.org/10.5194/nhess-9-2049-2009

Llasat, M.C., Llasat-Botija, M., Prat, M.A., et al. (2010a). Highimpact floods and flash floods in Mediterranean countries: the FLASH preliminary database. Adv. Geosci., 23, 47-55. http:// dx.doi.org/10.5194/adgeo-23-47-2010

Llasat, M.C., Llasat-Botija, M., Rodriguez, A., and Lindbergh, S. (2010b). Flash floods in catalonia: A recurrent situation. Adv. Geosci., 26, 105-111. http://dx.doi.org/10.5194/adgeo-26-105-2010

Llasat, M.C., Turco, M., Quintana-Seguí, P., and Llasat-Botija, M. (2014). The snow storm of 8 March 2010 in Catalonia (Spain): A paradigmatic wet-snow event with a high societal impact. Nat. Hazards Earth Syst. Sci., 14(2), 427-441. http://dx.doi.org/10.5194 /nhess-14-427-2014

Llasat, M.C., López, L., Barnolas, M., and Llasat-Botija, M. (2008). Flash-floods in Catalonia: the social perception in a context of changing vulnerability. Adv. Geosci., 17(2007), 63-70. http:// dx.doi.org/10.5194/adgeo-17-63-2008

Llebot, J.E. (2010). Segon informe sobre el canvi climàtic a Catalunya, Institut d'Estudis Catalans i Generalitat de Catalunya, Departament de la Vicepresidència, Consell Assessor per al Desenvolupament Sostenible de Catalunya, Barcelona.

López-Moreno, J.I., Vicente-Serrano, S.M., Angulo-Martínez, M., Beguería, S., and Kenawy, A. (2010). Trends in daily precipitation on the northeastern Iberian Peninsula, 1955-2006. Int. J. Climatol., 30, 1026-1041. http://dx.doi.org/10.1002/joc.1945

Lorenzo-Lacruz, J., Vicente-Serrano, S.M., López-Moreno, J.I., Morán-Tejeda, E., and Zabalza, J. (2012). Recent trends in Iberian streamflows (1945-2005). J. Hydrol., 414-415, 463-475. http:// dx.doi.org/10.1016/j.jhydrol.2011.11.023

Majone, B., Bovolo, C.I., Bellin, A., Blenkinsop, S., and Fowler, H.J. (2012). Modeling the impacts of future climate change on water resources for the Gállego river basin (Spain). Water Resour. Res., 48(1), 1-18. http://dx.doi.org/10.1029/2011WR0 10985

Martín, C. and Navascués, B. (2004). Estimation of structure functions for the analysis of two-meter temperature and relative humidity, in SRNWP/HIRLAM Workshop on Surface Processes, turbulence and mountain effects, Norrkoping (Sweeden).

Masson, V., Le Moigne, P., Martin, E., et al. (2013). The SURFE Xv7.2 land and ocean surface platform for coupled or offline simulation of earth surface variables and fluxes. Geosci. Model Dev., 6(4), 929-960. http://dx.doi.org/10.5194/gmd-6-9 29-2013

Navascués, B. (1997). Analysis of 2 meter Temperature and Relative Humidity.

Navascués, B., Calvo, J., Morales, G., et al. (2013). Long-term verification of HIRLAM and ECMWF forecasts over Southern Europe. History and perspectives of Numerical Weather Prediction at AEMET. Atmos. Res., 125-126, 20-33. http://dx.doi.org/10.1016/ j.atmosres.2013.01.010

Navascués, B., Rodríguez, E., Ayuso, J.J., and Jarvenoja, S. (2003). Analysis of surface variables and parameterization of surface processes in HIRLAM. Part II: Seasonal assimilation experiment. 
Noilhan, J. and Mahfouf, J. (1996). The ISBA land surface parameterisation scheme. Glob. Planet. Change, 13(1-4), 145-159. http://dx.doi.org/10.1016/0921-8181(95)00043-7

Noilhan, J. and Planton, S. (1989). A Simple Parameterization of Land Surface Processes for Meteorological Models. Mon. Weather Rev., 117(3), 536-549. http://dx.doi.org/10.1175/1520-0493(1989) $117<0536$ :ASPOLS $>2.0$. CO;2

Paris Anguela, T., Zribi, M., Hasenauer, S., Habets, F., and Loumagne, C. (2008). Analysis of surface and root-zone soil moisture dynamics with ERS scatterometer and the hydrometeorological model SAFRAN-ISBA-MODCOU at Grand Morin watershed (France). Hydrol. Earth Syst. Sci. Discuss., 5(6), 1903-1926. http://dx.doi. org/10.5194/hessd-5-1903-2008

Quintana Seguí, P., Ribes, A., Martin, E., Habets, F., and Boé, J. (2010). Comparison of three downscaling methods in simulating the impact of climate change on the hydrology of Mediterranean basins. J. Hydrol., 383(1-2), 111-124. http://dx.doi.org/10.1016/j. jhydrol.2009.09.050

Quintana-Seguí, P. (2011). Documentación técnica de SAFRAN/ E, Roquetes (Tarragona).

Quintana-Seguí, P., Habets, F., and Martin, E. (2011). Comparison of past and future Mediterranean high and low extremes of precipitation and river flow projected using different statistical downscaling methods. Nat. Hazards Earth Syst. Sci., 11 (5), 1411-1432. http://dx.doi.org/10.5194/nhess-11-1411-2011

Quintana-Seguí, P., Le Moigne, P., Durand, Y., et al. (2008). Analysis of near-surface atmospheric variables: Validation of the SAFRAN analysis over France. J. Appl. Meteorol. Climatol., 47, 92-107. http://dx.doi.org/10.1175/2007JAMC1636.1

Ranjard, L., Dequiedt, S., Chemidlin Prévost-Bouré, N., et al. (2013) Turnover of soil bacterial diversity driven by wide-scale environmental heterogeneity. Nat. Commun., 4, 1434. http://dx.doi.org/10. 1038/ncomms 2431

Ritter, B. and Geleyn, J.-F. (1992). A Comprehensive Radiation Scheme for Numerical Weather Prediction Models with Potential Applications in Climate Simulations. Mon. Weather Rev., 120(2), 303-325. http://dx.doi.org/10.1175/1520-0493(1992)1 20<0303: ACRSFN $>2.0 . \mathrm{CO} ; 2$

Rodríguez, E., Navascués, B., Ayuso, J.J., and Järvenoja, S. (2003). Analysis of surface variables and parameterization of surface processes in HIRLAM. Part I: Approach and verification by parallel runs.

Rodríguez, J.M.M. (2005). A Preliminary General Assessment of the Impacts in Spain Due to the Effects of Climate Change.

Rüdiger, C., Calvet, J. C., Gruhier, C., Holmes, T.R.H., de Jeu, R.A.M., and Wagner, W. (2009). An Intercomparison of ERSScat and AMSR-E Soil Moisture Observations with Model Simulations over France. J. Hydrometeorol., 10(2), 431-447. http://dx.doi.org/ 10.1175/2008JHM997.1

Ruin, I., Creutin, J.D., Anquetin, S., and Lutoff, C. (2008). Human exposure to flash floods-Relation between flood parameters and human vulnerability during a storm of September 2002 in Southern France. J. Hydrol., 361(1-2), 199-213. http://dx.doi.org/10. 1016/j.jhydrol.2008.07.044
Sauquet, E. and Catalogne, C. (2011). Comparison of catchment grouping methods for flow duration curve estimation at ungauged sites in France. Hydrol. Earth Syst. Sci., 15(8), 2421-2435. http:// dx.doi.org/10.5194/hess-15-2421-2011

Soci, C. and Bazile, E. (2013). EURO4M Project-REPORT D2.5 New MESAN-SAFRAN downscaling system.

Sumner, G.G., Romero, R., Homar, V., Ramis, C., Alonso, S., and Zorita, E. (2003). An estimate of the effects of climate change on the rainfall of Mediterranean Spain by the late twenty first century. Clim. Dyn., 20, 789-805. http://dx.doi.org/10.1007/s00382-0030307-7

Szczypta, C., Calvet, J.C., Albergel, C., et al. (2011). Verification of the new ECMWF ERA-Interim reanalysis over France. Hydrol. Earth Syst. Sci., 15(2), 647-666. http://dx.doi.org/10.5194/hess15-647-2011

Taillefer, F. (2002). CANARI Technical Documentation based on ARPEGE cycle CY25T1 (AL25T1 for ALADIN), Toulouse (France).

Thirel, G., Rousset-Regimbeau, F., Martin, E., and Habets, F. (2008). On the Impact of Short-Range Meteorological Forecasts for Ensemble Streamflow Predictions. J. Hydrometeorol., 9(6), 13011317. http://dx.doi.org/10.1175/2008JHM959.1

Turco, M. and Llasat, M.C. (2011). Trends in indices of daily precipitation extremes in Catalonia (NE Spain), 1951-2003. Nat. Hazards Earth Syst. Sci., 11(12), 3213-3226. http://dx.doi.org/10.5194/ nhess-11-3213-2011

Turco, M., Marcos, R., Quintana-Seguí, P., and Llasat, M.C. (2014).Testing instrumental and downscaled reanalysis time series for temperature trends in NE of Spain in the last century. Reg. Environ. Chang., 14(5), 1811-1823. http://dx.doi.org/10.1007/s10113 $-012-0363-9$

Turco, M., Quintana-Seguí, P., Llasat, M.C., Herrera, S., and Gutiérrez, J.M. (2011). Testing MOS precipitation downscaling for ENSEMBLES regional climate models over Spain. J. Geophys. Res. Atmos., 116(D18). http://dx.doi.org/10.1029/20 11JD016166

Uppala, S. M., KÅllberg, P.W., Simmons, A.J., et al. (2013). The ERA-40 re-analysis. Quart. J. Roy. Meteor. Soc., 131, 2961-3012. http://dx.doi.org/10.1256/qj.04.176

Velázquez, J.A., Anctil, F., and Perrin, C. (2010). Performance and reliability of multimodel hydrological ensemble simulations based on seventeen lumped models and a thousand catchments. Hydrol. Earth Syst. Sci., 14(11), 2303-2317. http://dx.doi.org/10.5194/hess- 14-2303-2010

Vidal, J.P., Martin, E., Franchistéguy, L., Baillon, M., and Soubeyroux, J.M. (2010). A 50-year high-resolution atmospheric reanalysis over France with the Safran system. Int. J. Climatol., 30(11), 1627-1644. http://dx.doi.org/10.1002/joc.20 03

Vrac, M., Drobinski, P., Merlo, A., Herrmann, M., Lavaysse, C., Li, L., and Somot, S. (2012). Dynamical and statistical downscaling of the French Mediterranean climate: Uncertainty assessment. Nat. Hazards Earth Syst. Sci., 12(9), 2769-2784. http://dx.doi.org/10. 5194/nhess-12-2769-2012 